\title{
NOTAS SOBRE O COLAPSO DA CIÊNCIA NO BRASIL
}

\author{
NOTES ON THE COLLAPSE OF SCIENCE IN BRAZIL
}

NOTAS SOBRE EL COLAPSO DE LA CIENCIA EN BRASIL

\author{
João dos Reis Silva Júnior \\ Doutor em Educação \\ Pós-doutorado em Economia na Universidade de São Paulo \\ Professor Titular da Universidade Federal de São Carlos \\ jr@ufscar.br
}

Everton Henrique Eleuterio Fargoni

Doutorando em Educação na Universidade Federal de São Carlos

Mestre em Educação na Universidade Federal de São Carlos everttonfargoni@gmail.com

\begin{abstract}
Resumo: Neste artigo, problematizamos as razões da crise da ciência brasileira, tendo como epicentro da análise o colapso do financiamento de pesquisas na segunda década do século XXI. Nesse contexto, com reformas políticas neoliberais e bloqueio dos fundos de financiamento, as universidades estatais brasileiras e seus pesquisadores encaram um dos momentos mais críticos para produzirem conhecimento. Nesse propósito, inicialmente recuperamos evidências da conjuntura que antecede e sucede as eleições de 2018 até a circunstância global do período analisado. Em seguida, brevemente, refletimos como o capital financeiro absorve a ciência reduzindo-a em tecnociência. Apresentamos dados da decadência no financiamento público à ciência e pesquisa. Analisamos o movimento da história política brasileira e seu processo de mudança no modelo econômico para o regime de predominância financeira, com início na década de 1990 por meio da Reforma do Aparelho do Estado. Configuração econômica que permanece na base política brasileira na regulação das contas públicas. Por fim, produzimos notas exploratórias sobre o colapso da ciência no Brasil. Trata-se de um artigo que analisa e faz crítica a reconfiguração por que se passa a universidade estatal, o trabalho do pesquisador e o decréscimo do fomento à pesquisa no Brasil.
\end{abstract}

Palavras-chave: ciência brasileira; educação superior; financeirização; financiamento; reforma do Estado.

Abstract: In this article, we problematize the reasons for the crisis in Brazilian science, with the collapse of research funding in the second decade of the 21 st century as the epicenter of the analysis. In this context, with neoliberal political reforms and blocked funding, Brazilian state universities and their researchers face one of the most critical moments for producing knowledge. In this purpose, we initially recover evidence from the conjuncture preceding and succeeding the 2018 elections to the overall circumstance of the analyzed period. Then, briefly, we reflect how the financial capital absorbs science reducing it into technoscience. We present data of the decline in public funding for science and research. We analyze the movement of Brazilian political history and its process of change in the economic model to a financially dominant regime, beginning in the 1990s through the Reform of the State Apparatus. Economic configuration that remains in the Brazilian political base in the regulation of public accounts. Finally, we produce exploratory notes on the collapse of science in Brazil. This is an article that analyzes and criticizes the reconfiguration that the state university is going through, the work of the researcher, and the decrease of research funding in Brazil.

Keywords: brazilian science; higher education; financialization; financing; State reform.

Resumen: En este artículo, problematizamos las razones de la crisis de la ciencia brasileña, con el colapso de la financiación de la investigación en la segunda década del siglo XXI como epicentro del análisis. En este contexto, con las reformas políticas neoliberales y el bloqueo de los fondos de financiación, las universidades estatales brasileñas y sus investigadores se enfrentan a uno de los momentos más críticos para la producción de conocimiento. En este propósito, recuperamos inicialmente la evidencia de la coyuntura que precede y sucede a las elecciones de 2018 hasta la circunstancia global del periodo analizado. Luego, brevemente, reflejamos cómo el capital financiero absorbe la ciencia reduciéndola a tecnociencia. Presentamos datos del descenso de la financiación pública de la ciencia y la investigación. Analizamos el movimiento de la historia política brasileña y su proceso de cambio de modelo económico para el régimen de predominio financiero, a partir de la década de 1990 mediante la Reforma del Aparato del Estado. Configuración económica que permanece en la base política brasileña en la regulación de las cuentas públicas. Por último, elaboramos notas exploratorias sobre el colapso de la ciencia en Brasil. Este es un artículo que analiza y critica la reconfiguración que vive la universidad estatal, el trabajo del investigador y la disminución del fomento de la investigación en Brasil.

Palabras clave: ciencia brasileña; la educación superior; financiación; financiación; reforma del Estado.

Para citar - (ABNT NBR 6023:2018)

SILVA JÚNIOR, João dos Reis; FARGONI, Everton Henrique Eleuterio. Notas sobre o colapso da ciência no Brasil. Eccos Revista Científica, São Paulo, n. 58, p. 1-18, e20850, jul./set. 2021. Disponível em: https://doi.org/10.5585/eccos.n58.20850. 


\section{Introdução}

Após as eleições de 2018 no Brasil, incógnitas dominaram o caminho que o país tomaria. Dizemos incógnitas, devido ao silogismo - se o presidente eleito foi um Deputado improdutivo por 3 décadas e acumulou polêmicas, logo a gestão presidencial de alguém com histórico problemático também seria nutrido de controvérsias. De fato, após quase 3 anos de mandato como presidente, Bolsonaro fez das incógnitas de outrora o tormento diário de milhões de brasileiros. Tal martírio, é uma combinação que Silva Júnior e Fargoni (2020) chamaram de "a necropolítica brasileira" em razão de práticas de cunho fascista pactuada com os ideais neoliberais.

A importância de notar essas marcas, deve-se ao fato que em 2020 a população mundial viveu o momento histórico da pandemia da Corona Virus Disease (COVID-19). Para responder este acontecimento de nível planetário, as nações conectaram cientistas para que, mutuamente numa corrida contra o tempo, pudessem decodificar o novo vírus e produzissem a vacina em

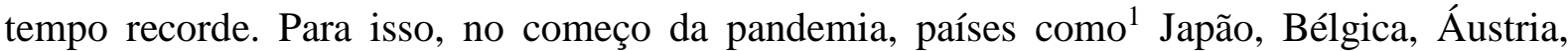
Estados Unidos, Catar, Irã entre outros, disponibilizaram mais de $10 \%$ de seus PIB para fomentar estudos no enfrentamento da doença.

No Brasil foi diferente em face da corrupção envolvendo a importações dos imunizantes. Enquanto os números de contaminação e mortes aumentavam em todo planeta, em vez do governo brasileiro aproveitar os recursos do país aumentando o financiamento de pesquisas, mesmo em caráter emergencial, o que aconteceu foi uma sucessão de atos de deboche e negacionismo que se colocava como um véu para a referida corrupção. Foi e ainda é uma clara demonstração do desprezo pela ciência brasileira e, sobretudo, com o cientista brasileiro. Desdém que não atingiu somente a comunidade científica, mas também a vida de centenas de milhares de pessoas. Porque até no início do mês de agosto de 2021, momento que completou um e ano meio de pandemia no Brasil, foram registradas mais de 560 mil mortes por covid-19.

A negligência com a pesquisa científica no Brasil não começou com Bolsonaro, ele acentuou o declínio. O financiamento em pesquisas está em decréscimo desde 2016, culminando nos piores números ao mesmo tempo que a sociedade civil brasileira mais precisou da ciência. Segundo dados da Sociedade Brasileira para o Progresso da Ciência (SBPC) e Lei Orçamentária Anual (LOA), Bolsonaro contingenciou entre 2019 e 2021 mais de 12 bilhões e meio de reais do Fundo Nacional de Desenvolvimento Científico e Tecnológico (FNDCT).

\footnotetext{
${ }^{1}$ Fonte: Universidade de Columbia; Universidade Sungkyunkwan e Universidade Eskisehir Osmangazi. Coronavírus: os 10 países que mais gastaram para enfrentar a pandemia de covid-19. BARRÍA, C. BBC News Brasil. 19 mai. 2020. Disponível em: https://www.bbc.com/portuguese/internacional-52721417. Acesso em: 05 ago. 2021
} 
Valor que não foi desbloqueado nem no momento mais crítico da pandemia, ocasião na qual ainda não haviam vacinas.

Nessa conjuntura, contradições permeiam a Educação Superior e, mais precisamente na pós-graduação, nível em que se predomina² a produção de conhecimento no país. Uma das contradições está, por exemplo, em dados como os divulgados pela empresa Clarivate Analytics a pedido ${ }^{3}$ da CAPES, mostrando que pesquisadores de pós-graduação nas universidades públicas brasileiras produziram entre 2011 e 2017 mais de 250 mil artigos científicos, pondo o Brasil na décima terceira posição no ranking mundial de produção científica. O contrassenso ocorre no volume de produção de conhecimento realizado ao passo que os fundos de financiamento à pesquisa são reduzidos.

Tais dados, como da produção de artigos são bastante significativos, mas preocupantes, uma vez que o governo tem anunciado sucessivos cortes no orçamento do setor, resultando no trabalho do pesquisador cada vez mais orientado pelo capital financeiro. Isto é, em tempos de negacionistas em aliança com neoliberais, a ciência virou produto e reduzida à tecnociência (SILVA JÚNIOR; FARGONI, 2020). Este é ponto central deste artigo. À medida que pesquisas científicas são cada vez mais necessárias no cotidiano global, seja por soluções sociais ou econômicas, na recente história do Brasil os pesquisadores produzem conhecimento munidos de incertezas. Pois a ciência é negada e desacreditada pelos líderes políticos do governo. Além disso, observamos a precarização da Educação Superior pública em consequência da mudança do modelo de financiamentos das pesquisas, por efeito da predominância da inovação e tecnologia com finalidade produtiva.

Este artigo, está estruturado em três partes, discute aspectos desse processo histórico até o epidêmico ano de 2021 e, como o financiamento da pesquisa científica no Brasil figura nessa conjuntura. A primeira parte caracteriza brevemente como o capital financeiro absorve a tecnociência como força motriz de produção de valor. A segunda apresenta dados do desinvestimento em ciência que vem acontecendo no Brasil desde 2016, procurando estabelecer razões sobre a crise no financiamento da pesquisa. Por fim, a terceira parte problematiza as razões políticas e econômicas que esboçaram nas últimas três décadas o colapso da ciência brasileira, tendo como epicentro do declínio em 2021.

\footnotetext{
${ }^{2}$ Universidades públicas realizam mais de $95 \%$ da ciência no Brasil. Universidade Federal de São Paulo, UNIFESP. 16 abr. 2019. Disponível em: https://www.unifesp.br/noticias-anteriores/item/3799-universidades-publicas-realizam-mais-de-95-da-ciencia-no-brasil. Acesso em: 05 ago. 2021.

${ }^{3}$ Fonte: https://www.gov.br/capesimages/stories/download/diversos/17012018-CAPES-InCitesReport-Final.pdf. Acesso em: 05 ago. 2021.
} 


\section{Tecnociência no capital financeiro}

Antes de aprofundarmos em questões específicas sobre financiamento de pesquisas no Brasil, reiteramos a importância de entender parte da conjuntura global em tempos de crise epistêmica da ciência. Pois em tempos de urgência no aumento de investimentos em ciência aplicada, ocorre a mercantilização máxima de produtos provenientes da ciência - razão da tecnociência. A mercantilização é componente tático do capital financeiro, isso ocorre sob regras do mercado devido ao lucro, concorrência e demanda. A pandemia não ficou de fora deste circuito. Em março de 2021, 10 países predominavam ${ }^{4}$ no controle de produção das vacinas contra covid-19. Além da corrida científica pela fórmula da vacina, aconteceu a corrida mercadológica por patentes do imunizante e, por conseguinte, o controle de produção de insumos e do produto final.

Segundo a Organização Mundial de Saúde (OMS), no início de fevereiro cerca de 200 milhões de vacinas contra covid-19 foram administradas. Porém, $75 \%$ dessas vacinas, estão em posse de apenas 10 países ricos. Nesse contexto, o Brasil até metade de 2021 não conseguiu produzir vacina própria sem realizar parceria com instituições de outros países, ora pelo governo não participar dos acordos internacionais, ora por priorizar tratamentos ${ }^{5}$ sem comprovação científica. Dessa forma, há aproveitamento do capital financeiro dos países de hegemonia econômica, visto que o capital financeiro não deixa lastro, busca lacunas em toda esfera pública para transformar profissões, negócios e propriedades em mercadorias. Basicamente, é a transformação do direito público em mercadoria. Neste caso, o direito à vacina.

Reconhecemos como necessária esta reflexão, pelo fato que a ciência brasileira passa por uma crise histórica de financiamento sem precedentes. Desde o início da pandemia, a bandeira da ciência tornou-se popular nas mídias sociais em todo planeta. Porém, no caso brasileiro, motivado por negacionistas do governo federal, tendo como principal porta-voz o presidente, o investimento em pesquisas que deveria ser uma das prioridades públicas em tempos de crises econômica e sanitária, passou a ser tratada como algo fútil e irrelevante para sociedade, inclusive as universidades - conforme declaração ${ }^{6}$ do Ministro da Educação Milton Ribeiro no dia 10 de agosto de 2021, ao dizer que universidade tem que ser "para poucos", pois, segundo ele, as universidades "não são tão úteis à sociedade".

\footnotetext{
${ }^{4}$ Vacinas contra covid: por que países ricos não quebram patentes para acelerar vacinação contra covid-19? NAVAS, María E. BBC News Brasil, 22 mar. 2021. Disponível em: https://www.bbc.com/portuguese/internacional-56454630. Acesso em: 05 ago. 2021.

5 Bolsonaro insiste em 'tratamento precoce' contra Covid-19 mesmo sem comprovação; não há medicamentos para prevenir a doença, mostram estudos. G1, 15 jan. 2021. Disponível em: https://g1.globo.com/bemestar/coronavirus/noticia/2021/01/15/bolsonaro-insiste-em-tratamento-precoce-sem-comprovacao-contra-acovid-estudos-mostram-que-nao-ha-prevencao-contra-a-doenca-com-ajuda-de-medicamentos.ghtml. Acesso em: 05 ago. 2021.

${ }^{6}$ Ministro da Educação defende que universidade seja 'para poucos'. G1, 10 ago. 2021. Disponível em:

https://g1.globo.com/educacao/noticia/2021/08/10/ministro-da-educacao-defende-que-universidade-seja-para-poucos.ghtml. Acesso em: 10 ago. 2021.
} 
Por motivos como esse, conforme indicamos na introdução, a declaração do Ministro da Educação concatena-se com o pacto dos fascistas e neoliberais brasileiros. Se para eles as universidades são não úteis à sociedade civil, tais instituições são bons exemplos para serem vendidos ou contratados como prestadores de serviços para organizações privadas. Discussão que ocorre nas minutas de projetos de lei como o Future-se ${ }^{7}$ e a Reforma Administrativa ${ }^{8}$.

Nesse sentido, a força de trabalho dos cientistas brasileiros, em preponderância, os pesquisadores nas universidades públicas, torna-se mercadoria. Soma-se nesse contexto, o trabalho exercido em pesquisas científicas pelos professores pesquisadores das universidades estatais, mais os pós-graduandos, que em muitos casos recebem bolsas de agências de fomento público, mas desenvolvem pesquisas em conjunto da iniciativa privada que, posteriormente, irão reter as possíveis patentes. A lógica desta relação pode ser sintetizada por Marx (1972) por meio do capital fictício, ao associarmos às ações de transformação em mercadorias cujo valor de mercado se determina diversamente do valor nominal. Esta mediação entre o trabalho do pesquisador e o capital fictício na realidade brasileira realiza-se de modo direto, pois o capital financeiro busca lucros, sendo assim o trabalho do pesquisador, crítico ou não, para o capital, tem que ser produtivo.

O capital pode ser entendido como o conjunto de ativos não humanos que são passíveis de comprar e vender em algum mercado. A universidade estatal brasileira, no contexto atual de crises, é também mercadoria como parte da riqueza e patrimônio para o capital financeiro. Pois no espaço científico acadêmico se estabelece o capital fictício, porque no processo de produção e de valorização da mercadoria, é crucial a redução do tempo de trabalho socialmente necessário e o aumento da mais-valia ou lucro. Logo, o pesquisador recebe menos pela produção imaterial, mas aumenta o tempo de trabalho para além do necessário.

É por isso que tecnociência se tornou componente matriz do capital financeiro. Com muita incidência nos fundos de financiamento da ciência brasileira, pois a tecnociência é a mudança epistêmica da ciência. Convertendo a produção de ciência aplicada e socializada com a humanidade, na ênfase de produção de novas tecnologias ou produtos comercializáveis - vide a vacina do covid-19. Assim como o capital fictício, a tecnociência possui propriedades econômicas associadas a rendas futuras. Por exemplo, projetos que dependam de recursos para produção de um software ou mecanismo eletrônico, recebem fomentos de investidores para que o valor futuro do produto final seja compensado com lucro, ou juros se o valor de investimento

\footnotetext{
${ }^{7}$ Projeto de Lei 3076/2020. Institui o Programa Universidades e Institutos Empreendedores e Inovadores - Future-se. Disponível em: https://www.camara.leg.br/proposicoesWeb/fichadetramitacao?idProposicao=2254321. Acesso em: 10 ago. 2021.

${ }^{8}$ Proposta de Emenda à Constituição 32/2020. Altera disposições sobre servidores, empregados públicos e organização administrativa. Disponível em: https://www.camara.leg.br/propostas-legislativas/2262083. Acesso em: 10 ago. 2021.
} 
no projeto for requerido por meio de empréstimo. É também um ativo transferível, porque a tecnociência é utilizada no mercado secundário, é vendida como solução antes do tempo e produz valor por "apostas" pelo que poderá render. Se o capital financeiro é entendido como capital representado por todas as formas conversíveis em dinheiro, a tecnociência é parte fulcral nessa máquina econômica.

Diante do exposto, pode-se entender o arcabouço jurídico que impõe a orientação do financiamento da pesquisa no país. Editais nacionais e estaduais são divulgados estruturados por critérios tecnocientíficos como inovação e empreendedorismo. Com finalidade mercantil, mas contraditoriamente exposto pelo fato do baixo valor investido, editais e ações políticas mostram o caminho da ciência brasileira ordenada pela tecnociência. A portaria $n^{\circ} 5.109$, de 16 de agosto de 2021, é um caso notório deste movimento. No plano em que foi definido as prioridades no âmbito do Ministério da Ciência, Tecnologia e Inovações, para projetos de pesquisa, de desenvolvimento de tecnologias e inovações, para o período 2021 a 2023. Dos 12 artigos expressos na Portaria, 7 apontam as áreas prioritárias. Em todas elas, as tecnologias são a sustentação.

Apesar do documento omitir a incoerência da intenção com a realidade. Pois sugerem que o Plano Plurianual contribua para a alavancagem em setores com maiores potencialidades para a aceleração do desenvolvimento econômico e social do país. Está mantido o contingenciamento de verbas, já reduzidas. Mesmo assim, a tecnociência é estabelecida como polo propulsor da pesquisa no Brasil. Dentre os vários setores, as tecnologias por via científica, orientam estudos para Desenvolvimento Sustentável, projetos no campo da área espacial, nuclear e cibernética. Para ciência aplicada em Biotecnologia, Inteligência Artificial e Nanotecnologia. Em Tecnologias de Produção para a Indústria, Agronegócio, Comunicação e Infraestrutura. No setor do Meio Ambiente por meio da Bioeconomia, Energias Renováveis, Cidades Inteligentes, Tratamento de poluição e Preservação Ambiental. Na área de Qualidade de Vida com tecnologias para Saúde, Segurança Hídrica, Saneamento Básico e Tecnologias Assistivas.

Por fim, a Promoção e divulgação da Ciências em três eixos, nos quais contemplam as ciências humanas absorvidas pelo capital financeiro - Ensino de Ciências, Comunicação Social e Educação Empreendedora. Todas as áreas são imprescindíveis. Porém, ao elencar prioridades na forma política em projetos de lei, emenda à constituição ou, nesta situação, em Portaria, deixa claros os propósitos que legitimam a tecnociência como componente do governo neoliberal. A busca de melhorar a condição econômica do país é válida, mas conforme expomos, a realidade não condiz com a prática governista, porque desde 2016 o índice de 
desindustrialização ${ }^{9}$ do país aumenta por ano. As tecnologias que deveriam ser parte da criação de novas indústrias brasileiras, estão postas como recursos ou descobertas do pesquisador brasileiro na produção de conhecimento para o capital estrangeiro.

Por isso, deslegitimar as universidades públicas brasileiras é interessante na forma política bolsonarista. $\mathrm{Na}$ ideologia que indicam cotidianamente, o senso crítico atrapalha as investidas do governo, pois o confrontam e expõem o contraditório. Sobre isso, tentam vencer o embate ideológico, usando táticas como a precarização da Educação Superior pública e bloqueando recursos da pesquisa científica. Porque sem financiamento não se produz ciência e pesquisadores ficam reféns de organizações privadas para continuarem seus projetos. Haja vista que em algumas áreas, como as ciências humanas, o foco não é lucro. Consequentemente, universidades e seus pesquisadores ficam condicionados a editais bastantes concorridos para conquistar financiamentos.

\section{Crise da ciência brasileira}

Enquanto a força de trabalho do pesquisador vale como mercadoria, a mercantilização da/na universidade estatal brasileira está cada vez mais intensa no presente de políticas neoliberais e reformas, que desde 2016 agravam a vida do trabalhador brasileiro. São reformas no âmbito da ciência, economia, educação e do trabalho: Novo Marco Legal da Inovação no Brasil, Lei $\mathrm{n}^{\mathrm{o}}$ 13.243, de 11 de janeiro de 2016; e o PEC do Teto dos Gastos, Emenda Constitucional $\mathrm{n}^{\circ}$ 95, de 15 de dezembro de 2016; Reforma Trabalhista - Lei $\mathrm{n}^{\circ}$ 13.467, de 13 de julho de 2017; Reforma da Previdência - Emenda Constitucional n ${ }^{\circ} 103$, de 12 de novembro de 2019 e a atualmente em trâmite, a Reforma Administrativa, Emenda à Constituição (PEC n ${ }^{\circ}$ 32/2020).

Estas leis são derivações da Reforma do Aparelho do Estado ( $C f$ SILVA JÚNIOR; SGUISSARDI, 1999) e sustentam o regime de predominância financeira que desde a década de 1990 estabelece mudanças em toda esfera pública no Brasil. Nessa conjuntura, a ciência brasileira integra um processo cada vez mais estrutural por efeito da redução do Estado na esfera pública, estando sob ordenamento jurídico e a serviço do mercado mundial de capitais. Isto ocorre por interesses que estão além do poder de voto da população, pois apesar dos altos investimentos em ciência, pesquisa e tecnologia no Brasil nos anos de governo Dilma Rousseff (2011-2016), a forma política que vem sendo praticada desde Fernando Henrique Cardoso

\footnotetext{
${ }^{9}$ Boom de commodities e desindustrialização colocam Brasil em encruzilhada. HARRIS, B. Financial Times e Folha de S. Paulo, 26 jul. 2021 . Disponível em: < https://www1.folha.uol.com.br/mercado/2021/07/boom-de-commodities-e-desindustrializacao-colocam-brasil-em-encruzilhada.shtml. Acesso em: 10 ago 2021.
} 
(1995-2002) é o antigo tripé macroeconômico, subdividido em três eixos: responsabilidade fiscal, metas de inflação e câmbio flutuante.

Esta forma de gestão econômica do país sempre limitou o financiamento de pesquisas no Brasil. E não mudou com Paulo Guedes, Ministro da Economia escolhido por Jair M. Bolsonaro. Este modelo econômico permanece há mais de vinte anos como polo condutor do esquema político e financeiro brasileiro. Mas, com a chegada de mais neoliberais nas pastas do governo, inclusive nos Ministérios da Educação e Ciência, Tecnologia e Inovações do Brasil, o que se percebe é o agravamento e descontrole dessa política, em consequência da subordinação do Brasil à outras hegemonias econômicas, sendo o Estados Unidos a principal delas.

Ao permanecer utilizando o mesmo modelo econômico de FHC, Lula, Dilma e Temer - Bolsonaro abriu mais espaço para a redução do Estado na esfera pública. O que aparentemente desacelerou algumas reformas e privatizações foi a pandemia, que transferiu o foco para as reais necessidades do povo brasileiro. Mesmo assim, o governo fez investidas irrisórias, como o auxílio emergencial reduzido ao valor de $\mathrm{R} \$ 150,00 \mathrm{em}$ momento recorde de desemprego ${ }^{10} \mathrm{e}$ reentrada do país no mapa da fome.

Nesse contexto, a pesquisa científica no Brasil seria uma das soluções para fins sociais e também econômicos, porém, os fundos de financiamento público estão integrados às mesmas crises. Constam no lote da PEC de gastos que bloqueou investimentos acima da previsão orçamentária anual por 20 anos. Ou seja, a Coordenação de Aperfeiçoamento de Pessoal de Nível Superior (CAPES) e o Conselho Nacional de Desenvolvimento Científico e Tecnológico (CNPq) estão "presos" sob as metas fiscais, um dos pilares do tripé macroeconômico. Posto que, o governo não pode "desrespeitar” o patamar de gastos e receitas. A contradição sobre esta realidade pesa, por exemplo, nas ações do governo na pandemia, que em vez de direcionar recursos para as universidades estatais e pesquisa científica, utilizou quase 90 milhões de reais em remédios cientificamente comprovados como ineficazes ${ }^{11}$ e mais de 20 milhões de reais em propagandas $^{12}$ do tratamento precoce dos mesmos fármacos.

Esta conjuntura não oferece boas perspectivas para o cientista brasileiro. Se a tendência política como vemos na linguagem neoliberal dos Ministérios de Bolsonaro permanecer, mesmo com o fato histórico e exemplar da pandemia, os indicadores de financiamento em pesquisa e ciência no Brasil tendem a ser inferiores do que os anos 2020 e 2021, em 2022.

\footnotetext{
${ }^{10}$ Brasil atinge recorde de 14,8 milhões de desempregados. Jornal da USP, 02 jun. 2021. Disponível em:

https://jornal.usp.br/atualidades/brasil-atinge-recorde-de-148-milhoes-de-desempregados/. Acesso em: 11 ago. 2021.

11 'Tratamento precoce': governo Bolsonaro gasta quase R\$ 90 milhões em remédios ineficazes, mas ainda não pagou Butantan por vacinas. SHALDERS, B. BBC News Brasil, 21 jan. 2021. Disponível em:

https://www.bbc.com/portuguese/brasil-55747043. Acesso em: 11 ago. 2021

${ }^{12}$ Governo gastou R \$ 23 milhões para divulgar tratamento precoce, mostram documentos; medida é ineficaz contra Covid. PALMA, G; PERNA, Y; MATOSO,

F. G1, 11 jun. 2021. Disponível em: https://g1.globo.com/politica/noticia/2021/06/11/governo-diz-que-gastou-r-23-milhoes-para-divulgar-tratamento-precoce-

ineficaz-contra-covid.ghtml. Acesso em: 11 ago. 2021.
} 
Gráfico 1 - Evolução dos Recursos para o Ministério da Ciência, Tecnologia e Inovações (MCTI) - (2009 a 2021). Orçamento em R \$ bilhões, atualizado pela inflação, Índice Nacional de Preços ao Consumidor Amplo (IPCA)

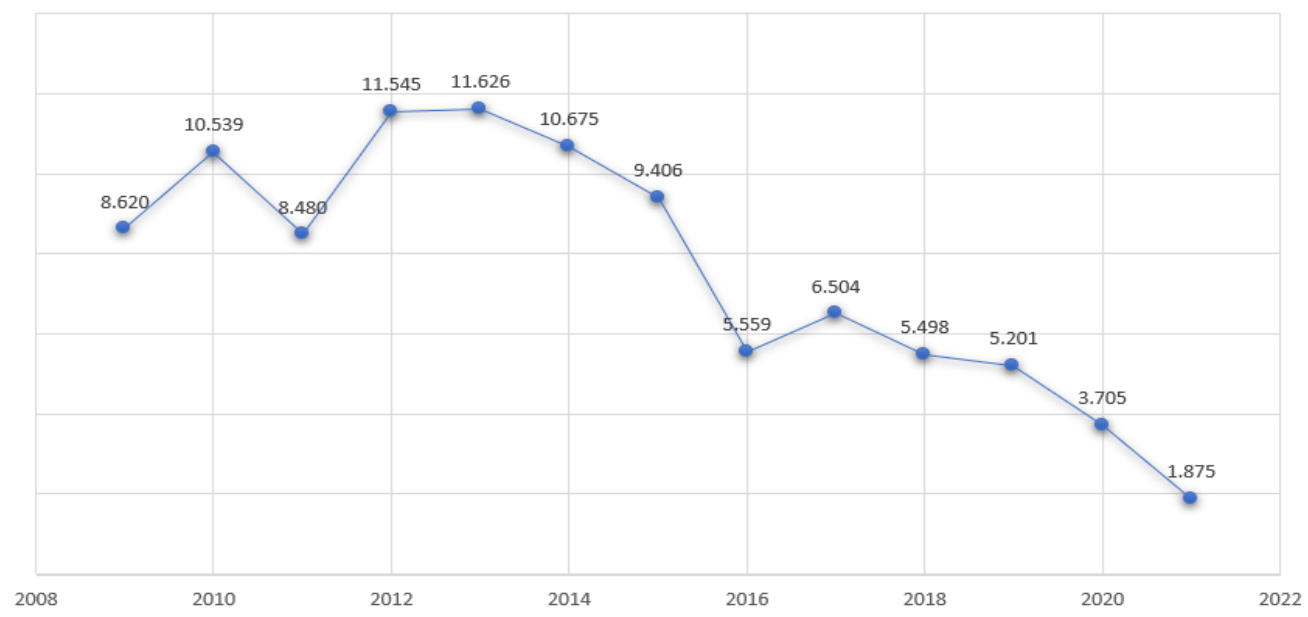

Fonte: Sociedade Brasileira para o Progresso da Ciência (SBPC) e Lei Orçamentária Anual (LOA), 2021. Gráfico criado pelos autores.

Nota-se por meio dos metadados nacionais do Gráfico 1 e, em seguida, no Gráfico 2, que o decréscimo no financiamento em pesquisa e ciência no Brasil tem fatores alinhados, como o contingenciamento entre 2019 e 2021 . Tendo por exemplo, mais de $90 \%$ da dotação dos recursos do Fundo Nacional de Desenvolvimento Científico e Tecnológico (FNDCT) em 2020 ainda bloqueados.

Gráfico 2 - Bloqueios contínuos do Fundo Nacional de Desenvolvimento Científico e Tecnológico (FNDCT), (2019 a 2021), valor em R $\$$ bilhões

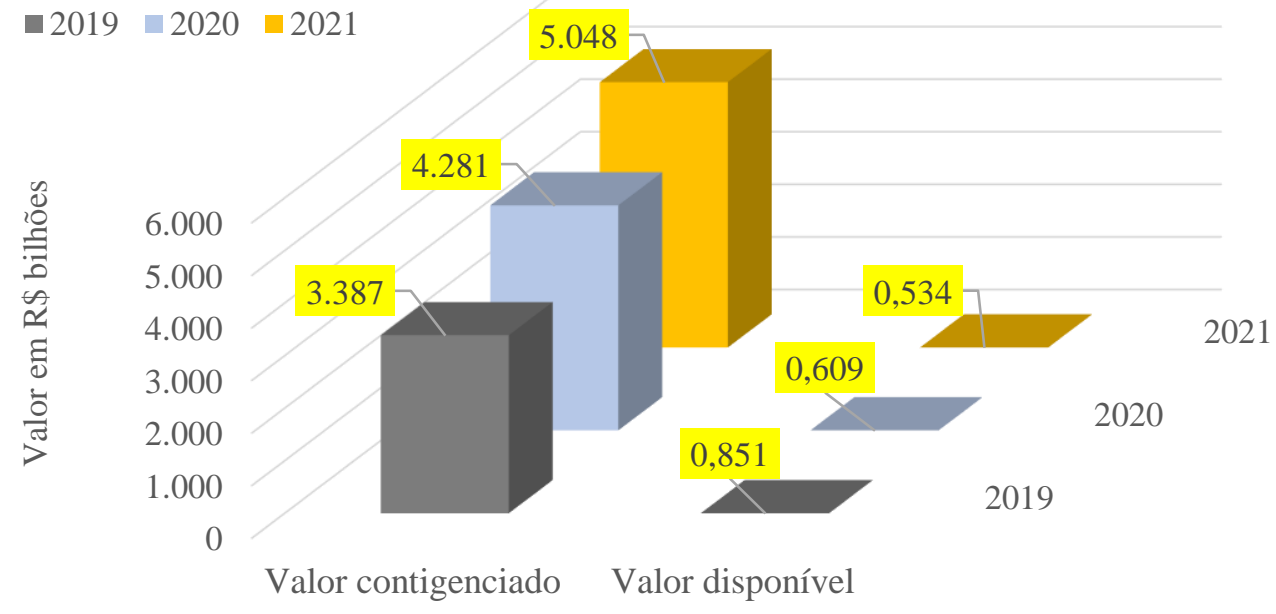

Fonte: Sociedade Brasileira para o Progresso da Ciência (SBPC) e Lei Orçamentária Anual (LOA), 2021. Gráfico criado pelos autores. 
Entre os anos de 2016 e 2021 é evidente o declínio no investimento em pesquisa, ciência e tecnologia no Brasil. Porém, nos três anos de gestão de Bolsonaro são 12.716 bilhões de reais contingenciados para ciência e tecnologia. Este decréscimo expõe a forma política e econômica que vem se desenhando no Brasil desde a década de 1990 e agrava-se após o impeachment de Dilma Rousseff, que teve nos seus últimos anos de presidência os maiores índices de investimento em pesquisa no Brasil.

A sucessão de cortes de bolsas e redução do financiamento das pesquisas no Brasil, provocaram indignação da comunidade científica, que aguardava para o ano de 2021 o desbloqueio dos recursos provenientes do Fundo Nacional de Desenvolvimento Científico e Tecnológico (FNDCT). Isto não afetou apenas as principais agências de fomento nacionais, como a CAPES e o CNPq, mas também instituições estatais de pesquisa, como a Fiocruz e EMBRAPA que tiveram reduções nos recursos em 2020 e 2021. No caso do orçamento da Empresa Brasileira de Pesquisa Agropecuária (EMBRAPA), vinculada ao Ministério da Agricultura, o investimento foi parcialmente recomposto. Mesmo assim, os valores à disposição em 2021 são $36 \%$ menores do que os de 2020.

Gráfico 3 - Variação orçamentária em números totais dos principais fundos de apoio à pesquisa científica e tecnológica (FNDCT, CNPq e CAPES): 2000 a 2020. Valores em R\$ Bilhões

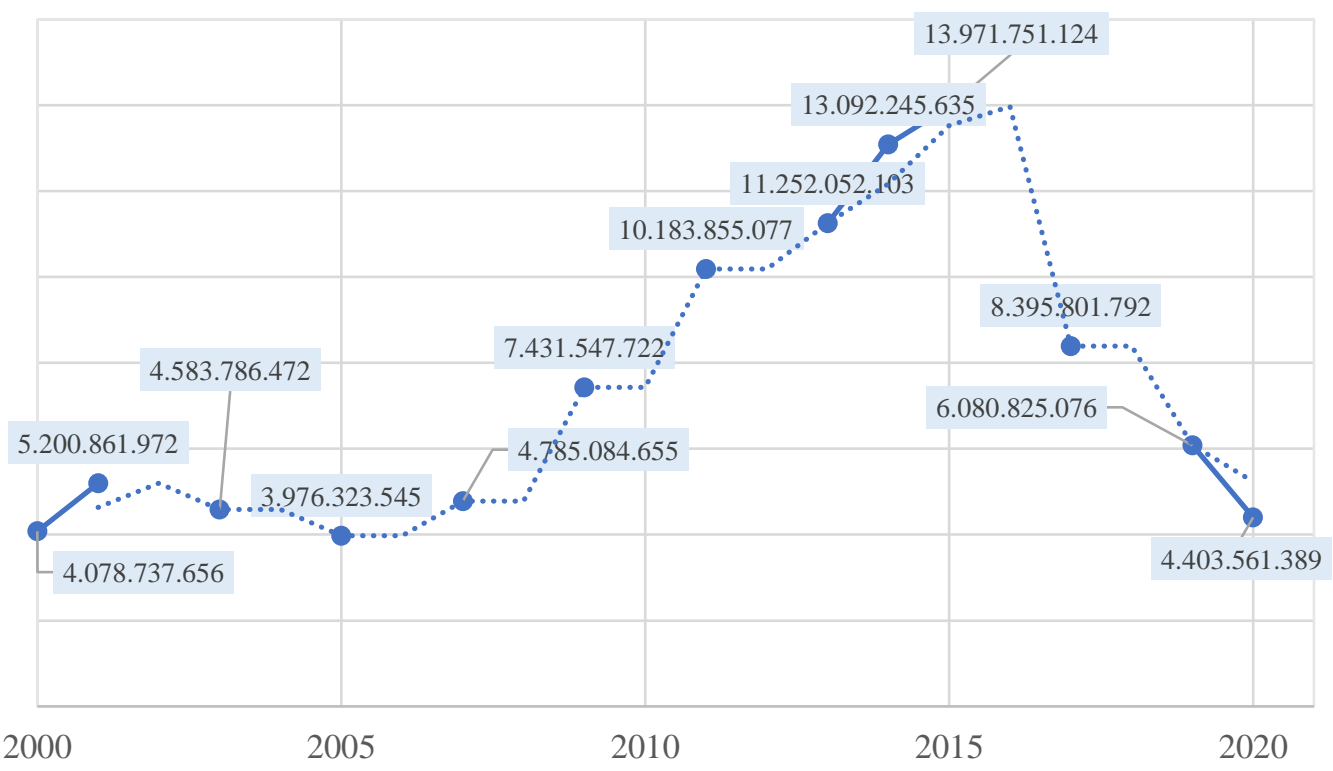

Fonte: Instituto de Pesquisa Econômica Aplicada (IPEA, 2021). Gráfico criado pelos autores.

O FDNCT permanece como principal ferramenta de financiamento à pesquisa e também à inovação tecnológica do governo federal, pois abastece com receitas de diversos segmentos da economia - como pecuária, petróleo, energia, saúde, biotecnologia. Em abril, o governo 
sancionou o orçamento de 2021, mantendo o expressivo bloqueio dos valores do Fundo Nacional de Desenvolvimento Científico e Tecnológico, desprezando a lei que foi aprovada pelo Congresso em 2020 que proibia novos contingenciamentos. Bolsonaro chegou a impor veto à lei para preservar a possibilidade de bloqueios. Porém, os parlamentares derrubaram no começo de 2021.

Para desviar a restrição imposta pelo Congresso, Bolsonaro fez uma manobra para postergar os efeitos da lei para 2022, atrasando a promulgação da derrubada do veto e conseguindo sancionar o primeiro orçamento. Dessa forma, os $\mathrm{R} \$ 5,6$ bilhões que compuseram o Fundo em 2021, somente R 534 milhões foram disponibilizados. O valor restante, 5 bilhões de reais, isto é, mais de $90 \%$ da dotação do Fundo, permanece contingenciado. Os pesquisadores esperam a liberação desses recursos, enquanto observam a queda no orçamento dos principais fundos de apoio à pesquisa científica e tecnológica, que em 2020 voltou aos indicadores de financiamento a ciência e pesquisa do ano 2000. Regresso de vinte anos em 3 anos.

Gráfico 4 - Orçamento detalhado dos principais fundos de apoio à pesquisa científica e tecnológica (FNDCT, CNPq e CAPES): 2000 a 2020

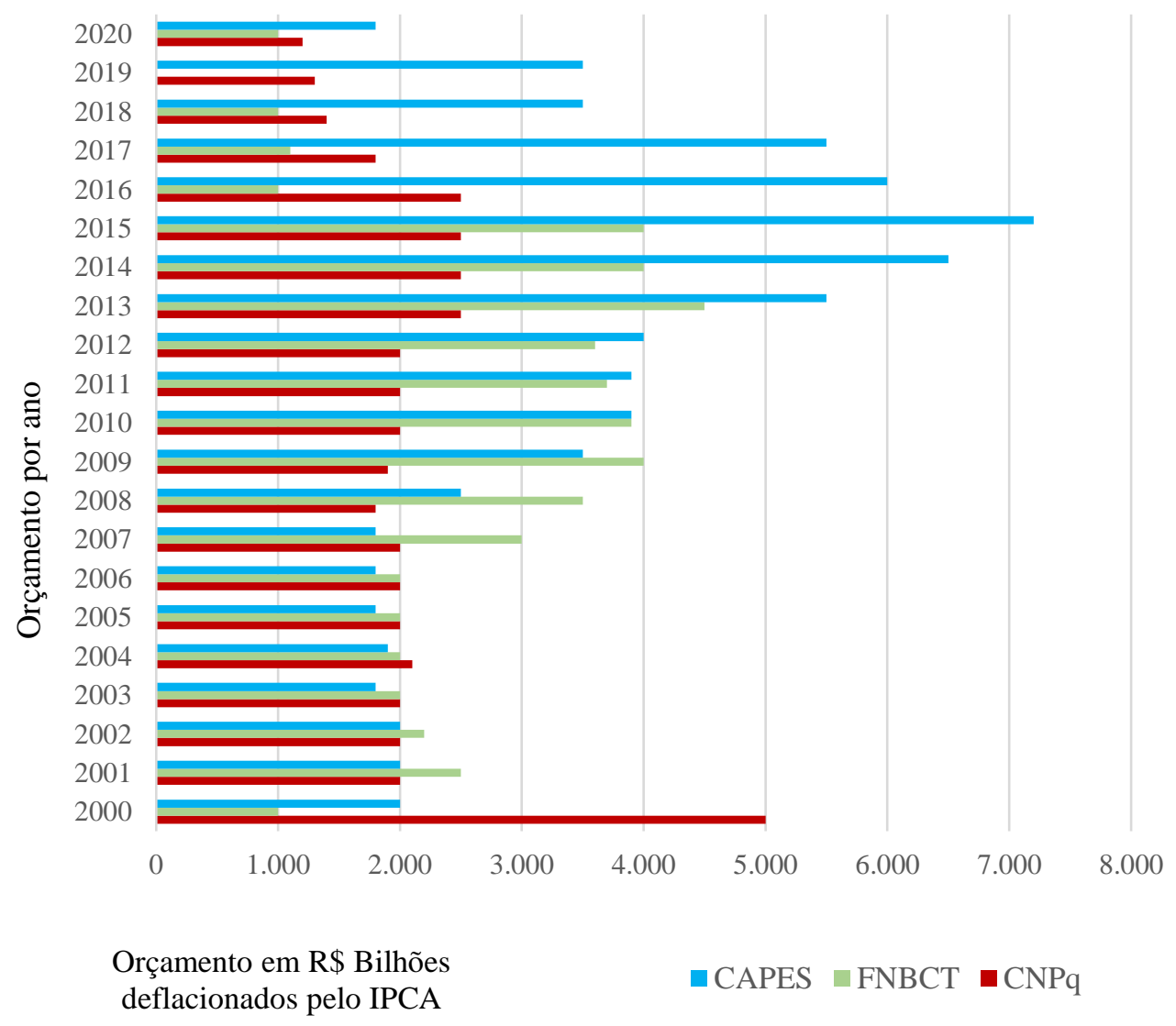

Fonte: Instituto de Pesquisa Econômica Aplicada (IPEA, 2021). Gráfico criado pelos autores. 
Há promessa de o Ministério da Economia liberar esses recursos contingenciados. Porém, isso depende da aprovação de uma nova lei comprometendo o empenho dos investimentos em pesquisa em 2021. A Financiadora de Estudos e Projetos (FINEP), que faz gestão dos recursos desse Fundo Nacional, recebe um percentual do Fundo para realizar este trabalho. Contudo, não dispõe de recursos para investir em subvenção econômica, um dos dispositivos principais para fomento à inovação em grandes e micro empresas no Brasil. Isso quer dizer que o fator industrialização nacional - um dos maiores instrumentos de produção de valor no capitalismo -, também não é foco do atual governo. O ínfimo respiro no primeiro semestre de 2021 adveio da CAPES, por meio da portaria do Ministério da Economia, que liberou pouco mais de R\$ 1 bilhão em crédito suplementar. Com esta medida, a agência de fomento contará em 2021 com quase (e apenas) R \$ 3 bilhões, valor inferior ao orçamento total do órgão em 2009.

\section{O movimento político-econômico da pesquisa no Brasil}

Chamamos de colapso da ciência brasileira a condição em que as universidades estatais e a pesquisa encontram-se em 2021. Fundos de financiamento contingenciados, orçamento ${ }^{13}$ operacional das instituições federais reduzidos, reformas políticas, ataques ${ }^{14}$ ideológicos entre outros contratempos, que estabelecem a precarização total da ciência nacional. O declínio é tão acentuado, que uma das maiores universidades públicas da América Latina, a Universidade Federal do Rio de Janeiro (UFRJ) corre risco de fechar em razão dos bloqueios de verba para as IFEs.

Este cenário, apesar de ser um diagnóstico da realidade recente, teve seu ovo da serpente posto no ninho científico nacional há mais de 20 anos, quando Fernando Henrique Cardoso sancionou em 29 de dezembro de 2000 a Lei № 10.168 que estabeleceu o Programa de estímulo à interação Universidade-Empresa para o apoio à inovação. Lei que consolidou a orientação das universidades estatais por meio de atividades econômicas. Destacamos também outras leis do período presidencial de FHC que complementam a lei supracitada: Lei 10.973/04 que regulamentou a relação entre capital privado e Estado; a Lei 9.279/96 que definiu as bases da Propriedade Industrial; a Lei 9.609/98 que definiu as regras do Programa de Computador, e a Lei 9.610/98 que estabeleceu as normas para o Direito Autoral.

\footnotetext{
${ }^{13}$ UFRJ detalha crise após bloqueio de verba e cita risco de fechar: 'Não dá para manter', diz vice-reitor. BARREIRA, G. G1, 12 mai. 2021. Disponível em: https://g1.globo.com/rj/rio-de-janeiro/noticia/2021/05/12/ufrj-detalha-crise-apos-bloqueio-de-verba-e-cita-risco-de-fechar-nao-da-para-manter-diz-vicereitor.ghtml. Acesso em: 05 ago. 2021.

${ }^{14}$ Ataques de Bolsonaro contra universidades seguem mesma lógica de Hugo Chávez. STUENKEL, O. El País, 12 ago. 2019. Disponível em: https://brasil.elpais.com/brasil/2019/08/13/opinion/1565648323_558328.html. Acesso em: 05 ago. 2021.
} 
Estas leis não foram estabelecidas por decisão política unilateral ou pressão dos partidos que predominavam no congresso na época. Estas leis são partes da forma política desenhada pelo capital financeiro desde a década de 1980 que teve como evento central a reunião que ficou conhecida como o Consenso de Washington ${ }^{15}$. Portanto, a nova racionalidade econômica estabelecida por meio de um regime cambial e controle dos gastos públicos, abriu uma série de privatizações que vem sendo realizada até os dias atuais. Instrumentos políticos que aterrorizam o cotidiano dos pesquisadores brasileiros. Pois, na atual realidade, projetos de lei como o Future-se que não deixa exposto nas minutas a descrição de privatizar as universidades e os institutos federais. Tem, na intenção proveniente do mercado de capitais aliado dos decisores políticos neoliberais, o interesse de transformar as IFEs em "Organizações Sociais (OS), para a busca de fomento e captação de recursos" na iniciativa privada (SILVA JÚNIOR; FARGONI, 2020).

Esta é a lógica determinante que está modificando o padrão do financiamento das pesquisas no Brasil. Conduz pesquisadores ao desenvolvimento de projetos, os quais têm que atender critérios de editais que sustentam os desígnios do capital financeiro - lucro por meio da inovação, novas tecnologias e o popular empreendedorismo. Conceito que está também empregado na realidade de alto índice de desemprego e forçado pelo mercado a sua ressignificação no cotidiano. Por exemplo, de motoristas e entregadores de aplicativo na forma de "você é seu chefe". Tudo isso compõe a redução do Estado na esfera pública.

O conceito "uberização" já pode ser aplicado aos cientistas brasileiros, posto que se há cortes nas verbas para financiamento público para pesquisas, um dos caminhos para os pesquisadores é prestar serviços. Na maioria das vezes sem vínculo empregatício. Realizando abertura de razão social ou registro de microempreendedor individual (MEI), para buscar fomento no setor privado. Situação que dificilmente se aplica para grandes áreas do conhecimento. Como por exemplo, a educação, que se produz conhecimento crítico e políticas públicas que não são de interesse dos grandes conglomerados internacionais ou do mercado produtivo.

Para compreender melhor esta racionalidade econômica imposta sobre os brasileiros e, que teve guarida em todas as presidências desde FHC, é necessário entender que após o Consenso de Washington e, na sequência com a Reforma do Aparelho do Estado, o Brasil passou a ser orientando por um regime de predominância financeira. Esta gerência econômica

\footnotetext{
${ }^{15}$ O Consenso de Washington foi um encontro realizado em 1989 em Washington entre representantes do governo norte-americano, Fundo Monetário Internacional, Banco Mundial, Banco Interamericano de Desenvolvimento e representantes de vários países com o objetivo de sistematizar e produzir o consenso sobre as principais diretrizes de política econômica com base no ideário neoliberal e que deveriam ser implementadas pelos países participantes do encontro. Estas diretrizes abrangiam as seguintes áreas: a) disciplina fiscal; b) priorização dos gastos públicos; c) reforma tributária; d) liberalização financeira; e) regime cambial; f) liberalização comercial; g) investimento direto; h) privatização; i) desregulação; j) propriedade intelectual. (BATISTA, 1994).
} 
tem como base a busca de hiatos, direitos e outros papéis que podem ser convertidos em dinheiro. Significa que o capital financeiro determina no que é para ser investido, a fim de gerar lucro por meio dos modos de produção e formar na sociedade civil o capital produtivo.

Nessa direção, o capital que é uma relação social criada pelos homens no decorrer das fases de desenvolvimento da humanidade, gerou a condição material superior, propiciando as circunstâncias para ampliar sua liberdade. Mas essa liberdade tem amparo

nas formas de (re)produção de sua existência, ou seja, cada vez mais é assegurada o domínio obtido sobre a natureza e, consequentemente, na produção de riquezas materiais. Observamos esse fato ${ }^{16}$ no expressivo número de mais de $50 \%$ da riqueza do Brasil estar retida em menos $1 \%$ da população. Para tal realidade, as últimas três décadas formam um movimento intrínseco à produção de valor. Enquanto o mercado de capitais aumenta a grandeza de valor sob a massa global aumentada, nisso inclui totalmente o Brasil, precariza-se a vida do trabalhador. Menos dinheiro e direitos e mais tempo de trabalho.

Nesse contexto, a pesquisa no Brasil e, consequentemente, o trabalho do pesquisador, são submetidas as métricas de eficácia devido a produção de conhecimento imaterial ser reconhecida como atividade produtiva. Isto pode ser incontestavelmente notado nos marcos estruturais da universidade estatal durante e após a gestão de Fernando Henrique Cardoso. Havendo em 26 de maio de 2010 o episódio exemplar no discurso do ex-Presidente Luiz Inácio Lula da Silva (2003-2010) na $4^{\text {a }}$ Conferência de Ciência, Tecnologia e Inovação, aproximando reitores das universidades estatais brasileiras com empresários. Feito com intento de discutir caminhos para autonomia universitária ao mesmo tempo que se consolidava o Consenso “Universidade-Governo-Empresa”. Ajustamentos e pactos do governo federal com o capital financeiro a fim de subverter o sentido da universidade pública.

De fato, isto ocorre, mas não pelo Future-se. Seguindo a tendência de desenvolvimento do capital que consolidou uma economia mundial ao integrar nações à lógica mercadológica, com base na indústria. Dilma Rousseff (2011-2016) apresentou em 01 de agosto de 2013 a primeira versão do Novo Marco Legal de Ciência, Tecnologia e Inovação, sancionada como lei (PL 13.243) três anos depois em 11 de janeiro de 2016. Estabelecendo os estímulos ao desenvolvimento de produção científica, à pesquisa e capacitação tecnológica para a inovação. Este foi o que podemos denominar de o ponto de partida do Future-se e, coincidentemente, iniciou a redução do financiamento das pesquisas em todo âmbito nacional.

\footnotetext{
${ }^{16}$ Seis brasileiros concentram a mesma riqueza que a metade da população mais pobre. Estudo da Oxfam revela que os $5 \%$ mais ricos detêm mesma fatia de renda que outros 95\% Mulheres ganharão como homens só em 2047, e os negros como os brancos em 2089. ROSSI, M. El País Brasil, 25 set. 2017. Disponível em: < https://brasil.elpais.com/brasil/2017/09/22/politica/1506096531_079176.html. Acesso em: 05 ago. 2021.
} 
Lula, Dilma e depois Temer, mantiveram o modelo econômico de FHC. Um regime que compõe a natureza do capital financeiro, marcado por contradições insolúveis e que produz riqueza para poucos, expandindo a desigualdade social. Fato de difícil superação na atual configuração da sociedade civil e explica o crescimento atenuado de concentração de rendas nos últimos anos. Nota-se essa racionalidade por meio das reformas políticas que desafiam a sobrevivência do trabalhador de base brasileiro. O pesquisador nesse processo encara o que chamamos de precarização do trabalho como parte do cotidiano e se sente mal, adoecido sob a lógica de um mercado produtivo que não busca intelectos, mas números.

Nesta exposição, o neoliberalismo brasileiro foi se propagando até o ponto máximo da entrada de Bolsonaro no poder político. Sendo ele, submisso do capital financeiro e propagador de discursos anticientíficos. Cena perfeita para que os "ultraliberais" façam da ciência brasileira um criadouro de cientistas que pesquisem e produzam conhecimento para os interesses deles. Apoiando a base ideológica do governo, que não quer saber que o financiamento de pesquisas é parte crucial da construção de uma soberania nacional, pois são subalternos das predileções de nações hegemônicas e grandes corporações com capital aberto.

É importante ressaltar o movimento desses planos nas décadas recentes da história do país estão sujeitos à lógica mercantil como exposto neste texto e beneficiam a minoria da sociedade brasileira ao mesmo tempo em que igualmente dá sustentação aos pesquisadores adeptos da tecnociência.

\section{Considerações finais}

Passadas cerca de três décadas da Reforma do Aparelho do Estado, o processo de redução do Estado na esfera pública brasileira continua em trâmite, acentuado pelas reformas políticas mais recentes e com forte incidência no âmbito da universidade pública e da ciência nacional. O Estado brasileiro, independente dos governantes e seus partidos, está desde a década de 1990 formando um conjunto de dispositivos legais para entregar as universidades estatais brasileiras para o capital financeiro. Após as eleições de 2018 esse movimento se intensifica. Por meio de ataques ideológicos direcionados às universidades públicas.

Por meio das evidências que apresentamos neste artigo, entendemos que o capital é condutor da financeirização das pesquisas no Brasil há mais de três décadas. Cerca a produção científica das universidades estatais para lucrar com o trabalho de pesquisadores, e se coloca no controle das instituições. Superando a orientação do financiamento das pesquisas e próximo, por meio dos projetos de lei que aqui destacamos, do domínio administrativo das instituições 
federais. Trata-se de uma intensa mudança, que há enfrentamento, a fim de resistir às forças políticas embrionadas nos consensos e pactos que marcam a recente história do Brasil.

Examinamos também o fato de a tecnociência se constituir no novo modelo epistêmico da ciência, sob a racionalidade do capital financeiro. Se para o capital financeiro toda brecha na sociedade civil é oportunidade para produzir dinheiro, a tecnociência é uma subdivisão da ciência que exaure a ciência de sua razão originária. É o que está acontecendo com a pesquisa no Brasil. Como destacamos, o colapso da ciência brasileira tem origem no regime de predominância financeira por meio do tripé macroeconômico. Ao passar das décadas e das gestões presidenciais que mantiveram o mesmo modelo econômico, as reformas neoliberais foram operacionalizadas e forjaram o atual estado crítico da pesquisa e ciência brasileira.

Os órgãos de fomento à pesquisa, como a CAPES e o CNPq, sob guarida nas atuais políticas neoliberais do governo Bolsonaro, não vislumbram nem metade dos recursos de pouco menos de meia década atrás. Se a atividade científica é fundamental para a promoção da emancipação humana, o Brasil vive dias de regresso. Sobre esses limites, buscamos mostrar que a mercantilização máxima das universidades está em curso. Primeiro com o Marco Legal da Ciência e Tecnologia, depois com o Future-se. A pesquisa científica pode ser reduzida a nicho, dada a possibilidade da privatização das IFEs, perda de autonomia das instituições e, por conseguinte, dos pesquisadores que já estão condicionados aos editais que, cobram produtividade e inovação ao mesmo tempo que promove a competição entre os pares.

No plano social, a alternativa é confrontar sem pessimismo e usar da inteligência brasileira para frear o avanço das práticas e políticas neoliberais que são presentes no cotidiano brasileiro. A pandemia do covid-19 foi um dos principais obstáculos nesse sentido. Impossibilitou manifestações, deixando os indignados reféns das mídias sociais para contrapor a forma política que vem sendo praticada por Bolsonaro. Muitos absurdos foram cometidos pelo atual governo, muito além com a ciência - foi contra os direitos humanos, a educação, o trabalho e, sobretudo, a economia.

Puxado pela inflação e desemprego recorde, Bolsonaro trouxe o Brasil de volta ao mapa $^{17}$ da fome e da miséria. Se o plano dos neoliberais do governo foi transformar universidades do Brasil em novos "Vales do Silício", o projeto está fracassado. Não se faz ciência sem verba e a soberania nacional é construída com políticas públicas bem determinadas para progresso de vários eixos, como a indústria. Sem ignorar nenhuma área. A universidade

\footnotetext{
${ }^{17}$ Índice de miséria no Brasil é recorde, puxado por inflação e desemprego. CAVALCANTE, L. UOL Economia, 12 ago. 2021. Disponível em: < https://economia.uol.com.br/noticias/redacao/2021/08/12/indice-de-miseria-brasil-recorde-inflacao-desemprego.htm. Acesso em: 12 ago. 2021.
} 
pública, a educação básica e a ciência brasileiras financiadas publicamente são pilares de uma nação e de soberania nacional.

\section{Referências}

BATISTA, P. N. A visão neoliberal dos problemas da América-Latina. USP: São Paulo, 1994.

BRASIL. Lei $n^{o} 1.310$, de 15 de janeiro de 1951. Cria o Conselho Nacional de Pesquisas, e dá outras providências. Disponível em: http://www.planalto.gov.br/ccivil_03/leis/19501969/11310.htm. Acesso em: 10 ago. 2021.

BRASIL. Lei $n^{\circ} 13.243$, de 11 de janeiro de 2016. Dispõe sobre estímulos ao desenvolvimento científico, à pesquisa, à capacitação científica e tecnológica e à inovação. Disponível em: http://www.planalto.gov.br/ccivil_03/_ato2015-2018/2016/lei/113243.htm. Acesso em: 10 ago. 2021

BRASIL. Emenda Constitucional $n^{\circ}$ 95, de 15 de dezembro de 2016. Altera o Ato das Disposições Constitucionais Transitórias, para instituir o Novo Regime Fiscal, e dá outras providências. Disponível em:

http://www.planalto.gov.br/ccivil_03/constituicao/emendas/emc/emc95.htm. Acesso em: 10 ago. 2021.

BRASIL. Lei $N^{o} 13.467$, de 13 de julho de 2017. Altera a Consolidação das Leis do Trabalho (CLT). Disponível em: http://www.planalto.gov.br/ccivil_03/_ato2015-

2018/2017/lei/113467.htm. Acesso em: 10 ago. 2021.

BRASIL. Emenda Constitucional $n^{o} 103$, de 12 de novembro de 2019. Altera o sistema de previdência social e estabelece regras de transição e disposições transitórias. Disponível em: http://www.planalto.gov.br/ccivil_03/constituicao/emendas/emc/emc103.htm. Acesso em: 10 ago. 2021.

BRASIL. Proposta de Emenda à Constituição no 32/2020. Altera disposições sobre servidores, empregados públicos e organização administrativa. Disponível em: < https://www.camara.leg.br/proposicoesWeb/fichadetramitacao?idProposicao=2262083. Acesso em: 10 ago. 2021.

BRASIL, Sociedade Brasileira para o progresso da ciência (SBPC). Entidades ligadas à ICTP.br pedem a parlamentares liberação imediata e integral do FNDCT. 31 mai. 2021. Disponível em: http://portal.sbpcnet.org.br/noticias/entidades-ligadas-a-ictp-br-pedem-aparlamentares-liberacao-imediata-e-integral-do-fndct/. Acesso em: 10 ago. 2021.

BRASIL, Portaria MCTI $N^{\circ} 5.109$, de 16 de agosto de 2021. Define as prioridades, no âmbito do Ministério da Ciência, Tecnologia e Inovações, no que se refere a projetos de pesquisa, de desenvolvimento de tecnologias e inovações, para o período 2021 a 2023. Disponível em: https://www.in.gov.br/web/dou/-/portaria-mcti-n-5.109-de-16-de-agosto-de-2021-338589059. Acesso em: 16 ago. 2021.

MARX, K. O Capital. London: Lawrence \& Wishart, v. III, 1972. 
SILVA JÚNIOR, J. R.; SGUISSARDI, V. Novas faces da educação superior no Brasil Reforma do Estado e mudanças na produção. Bragança Paulista: Edusf, 1999.

SILVA JÚNIOR, J. R.; FARGONI, E. H. E. Bolsonarismo: a necropolítica brasileira como pacto entre fascistas e neoliberais. Revista Eletrônica de Educação, v.14, 1-26, jan./dez. 2020.

SILVA JÚNIOR, J. R.; FARGONI, E. H. E. Tecnociência, industrialização e pesquisa na financeirização radical do capitalismo e da educação superior. Revista Inter Ação, 45(3), 569$581,2020$.

SILVA JUNIOR, J. R.; FARGONI, E. H. E. Future-se: o ultimato na universidade estatal brasileira. Educação e Sociedade, Campinas, v. 41, e239000, 2020a. 